\title{
Emergency laparoscopic common bile duct exploration and analysis of risk factors for post-procedure leak: A seven years' experience
}

\author{
Yousif Aawsaj, $\odot$ James Brown, $\odot$ Liam Horgan, Duncan Light
}

Northumbria Healthcare NHS Foundation Trust, United Kingdom

\begin{abstract}
Introduction: Laparoscopic common bile duct exploration (LCBDE) for choledocholithiasis in the emergency setting is challenging and technically demanding. This study aims to assess the safety and efficacy of emergency LCBDE and to analyze risk factors for post-operative bile leak.

Materials and Methods: A retrospective data collection was done over medical notes and electronic records of the patient for the period between January 2011 to October 2017. Merelythe emergency LCBDEs were involved in this series. All of the emergency LCBDEs performed were on the index admission. Univariate and multivariate analysis were caried out for the risk factors of bile leak post-procedure.

Results: 78 patients were undergone emergency LCBDE in the given period. 76 patients had a laparoscopic cholecystectomy as well as emergency LCBDE; two patients had previously undergone laparoscopic cholecystectomy. While choledochotomy was performed in 62 patients, 16 patients had a transcystic approach. All emergency LCBDEs were initiated laparoscopically, three (4\%) patients had to be converted to open procedure due to adhesions (one) and impacted stones (two). In 72 patients (\%89), the CBD was cleared in 72 patients (89\%) and 9 patients were considered to be in need of post-operative ERCP (6 for retained stone, 2 showing clear ducts, and 1 for continuous bile leak). Normal CRP and bilirubin values were significantly associated with post-operative bile leak.

Conclusion: Emergency laparoscopic common bile duct exploration is safe, feasible, and efficient in the emergency management of common bile duct stones.

Keywords: Bile leak; common bile duct stones; emergency; laparoscopic.
\end{abstract}

\section{Introduction}

Common bile duct stones are a common surgical diagnosis and can present in up to $20 \%$ of patients presenting with acute gallstone disease..$^{[1,2]}$ Emergency presentation of CBD stones can be in the form of acute cholangitis, acute pancreatitis, painful obstruction jaundice and acute cholecystitis. Both Endoscopic Retrograde Cholangio-Pancreatiticography (ERCP) followed by laparoscopic cholecystectomy (LC) and a single stage procedure of LC and laparoscopic common bile duct explorations (LCBDE) are recognised as equivalent treatment for CBD stones. ${ }^{[3,}$

${ }^{4]}$ Emergency LCBDE has been demonstrated to be a safe, 
feasible and effective management for acute presentation of CBD stone diseases. ${ }^{[5]}$ Choledochotomy and trancystic approaches in LCBDE are both valid options for treatment of CBD stones. Historically, a choledochotomy incision used to be drained via a T-tube; however primary choledochotomy incision closure without a T-tube has been shown to be safe and cost effective option. ${ }^{[6]}$ Bile leak following LCBDE and primary closure is one of the major potential complications of the procedure. One series has shown some potential risk factors of bile leak following LCBDE in the elective setting; this would help to predict patients at high risk of bile leak and may be used in considering other treatment options ${ }^{[7]}$ Many series have published data from heterogeneous groups of elective and emergency LCBDE results. ${ }^{[8-10]}$ In our series we demonstrate the feasibility and safety of exploring the CBD laparoscopically in the emergency setting specifically and show the outcomes in terms of duct clearance, hospital stay, operative time and complications. This series also identifies potential risk factors for bile leak following LCBDE in the emergency setting.

\section{Materials and Methods}

Patients were identified retrospectively from our database that had an emergency LCBDE between January 2011 and October 2017. All patients were consented for the procedure and Caldicott approval obtained from the local governance team. All patients had been admitted as an emergency and were investigated with serum blood tests in forms of full blood count, Liver function test, urea and creatinine, Amylase and CRP. All patients had ultrasound imaging and all patients included were confirmed to have CBD stones via MRCP and/or CT-scan.

Our criteria for emergency LCBDE were that a patient was admitted as emergency with evidence of CBD stones and CBD diameter of $10 \mathrm{~mm}$ or more. All patients had a LCBDE during their index admission.

Procedure: Patient position and port placement are as per standard for LC. Most of the patients had LC and LCBDE at the same time except for a few who had solely LCBDE due to previous LC. We adapted both transcystic and choledochotomy approaches depending on the diameter of cystic duct. When the transcystic approach failed, we converted to a choledochotomy if the anatomy was favourable. Exploration of the CBD was performed using a re-usable choledochoscope (3 $\mathrm{mm}$ in transcystic and $5 \mathrm{~mm}$ in choledochotomy) or disposable bronchoscope (Ambu Scope)
(3.8 $\mathrm{mm}$ in transcystic and $5 \mathrm{~mm}$ in choledochotomy). We used normal saline to irrigate and distend the CBD. A Dormia $^{\circledR}$ basket was used to retrieve any CBD stones. After transcystic exploration we clipped the cystic duct with Titanium or absorbable locking clips. We closed the choledochotomy incision using either PDS ${ }^{\circledR}$ or Vicryl ${ }^{\circledR}$ suture which could be of any size from $2 / 0$ to $4 / 0$, interrupted or continuous (depending on surgeons preference). LC was performed at the completion of the procedure; we always used two drains in the choldechostomy group (one sub hepatic and other sub-phrenic) and one subhepatic drain in transcystic group.

Our definitions of a bile leak post emergency LCBDE are:

1- Drains continue to leak bile more than $100 \mathrm{mls} /$ day for 3 days or more.

2- Evidence of abdominal pain and peritonism in the postoperative period necessitating the patient return to operating theatre.

3- Radiological evidence of large volume of intra-abdominal fluid collections.

We categorised factors which we thought they might associated with bile leak following emergency

LCBDE into three groups:

1- Demographic (Age, sex, diagnosis)

2- Bio-chemical and radiological (Bilirubin, CRP, WBC levels and CBD diameter)

3- Operative (suture type, technique of closure, size of suture and T-tube usage).

Analysis of risk factors for bile leak was performed using uni-variance and multi-variance analysis via logistic regression methods using SPSS 16.0.

\section{Results}

Seventy eight patients underwent emergency LCBDE. There were 55 female and 23 male patients; mean age for patients was $57 \pm 18$ years. Seventy six patients had a laparoscopic cholecystectomy as well as emergency LCBDE; two patients (2.5\%) had a previous laparoscopic cholecystectomy. Four patients (5\%) had a previous gastric bypass surgery that was already not suitable for ERCP. Eight patients $(10 \%)$ had unsuccessful ERCP and were referred for emergency LCBDE.

Patients presentations were primarily obstructive jaun- 
Table 1. Shows demographic, hospitalisation, diagnosis and complications

\begin{tabular}{|c|c|c|c|}
\hline \multicolumn{2}{|c|}{ Sex } & $55 \mathrm{~F}$ versus $23 \mathrm{~F}$ & Mean age 55 years \\
\hline \multirow{2}{*}{\multicolumn{4}{|c|}{$\begin{array}{l}\text { Approach } \\
\text { Hospitalisation }\end{array}$}} \\
\hline & & & \\
\hline 1 & Time to operation & 2.7 days & \\
\hline 2 & Post-operative stay & 4.6 days & \\
\hline 3 & Overall hospital stay & 7.5 days & \\
\hline \multicolumn{2}{|c|}{ Conversion rate } & $3 / 78$ & 1 adhesion, 2 impacted stones \\
\hline \multicolumn{2}{|c|}{ Duct clearance } & $72 / 78$ & 6 had already failed ERCP preop \\
\hline \multicolumn{2}{|c|}{ Bile leak } & $13 / 78$ & 9 re-lap, 1 ERCP, 3 conservative \\
\hline \multicolumn{2}{|c|}{$\begin{array}{l}\text { Death and Re-admission } \\
\text { Diagnosis }\end{array}$} & $3 / 78$ re-admission & $3 / 78$ death (medical reasons) \\
\hline 1 & Obstructive jaundice & $24 / 78$ & Deranged LFTs, normal inflammatory, thin wall GB \\
\hline 2 & Cholangitis & $19 / 78$ & Deranged LFTs, raise inflammatory markers \\
\hline 3 & Acute pancreatitis & $18 / 78$ & $\begin{array}{l}\text { Raise amylase more than } 400 \text { regardless other } \\
\text { finding }\end{array}$ \\
\hline 4 & Acute cholecystitis & $17 / 78$ & $\begin{array}{l}\text { Thick wall GB with/out deranged LFTs and raise } \\
\text { inflammatory markers }\end{array}$ \\
\hline
\end{tabular}

dice in 24 , cholangitis in 19, acute pancreatitis in 18 and acute cholecystitis in 17 patients (Table 1).

The mean time for patients waiting for surgery was $2.7 \pm 1.2$ days. The mean overall hospital stay was

$7.5 \pm 2.2$ days, while the average post-operative stay was $4.6 \pm 1.5$ days. A choledochotomy approach was performed in 62 patients, while a transcystic approach was followed in 16 patients. A transcystic approach was commenced in 23 patients and was successful in 16 patients. A transcystic approach was unsuccessful in seven patients because four had a large impacted stone, two anatomical difficulties and one when a $3 \mathrm{~mm}$ choledocoscope was not available. The mean operative time for trans-cystic and choledochotomy approaches were 106 and 135 minutes respectively. In emergency LCBDE group, three patients (4\%) had to be converted to an open procedure due to adhesions (one) and impacted bile duct stones (two). The CBD was cleared in $72 / 78$ patients $(89 \%)$. All the six patients who did not have the CBD cleared via laparoscopic CBD exploration proceeded to a post procedure ERCP (four of these patients had their CBD cleared from impacted stones with ERCP, one patient need laparotomy to clear the duct after failed attempt of ERCP and one his ERCP showed no stone).

Thirteen patients (16\%) had a post-operative bile leak. All thirteen occurred after a choledocotomy was performed (9 needed re-laparoscopy for drainage and wash out, 3 were treated conservatively and 1 needed ERCP to drain the biliary system). There were no post-operative bile leaks following a transcystic approach. A T-tube was used in 12 patients. Most of the $\mathrm{T}$ tube insertions were during the early years of this series. The reasons for utilising a $\mathrm{T}$ tube were impacted and/or missed stones in five patients, a difficult procedure and/or unhealthy tissue for primary closure in four patients and preference of the surgeons as part of their routine practice in three patients. In patients who had $\mathrm{T}$ tube insertion due to concern about impacted/missing stones, four had impacted stones which were cleared by ERCP and one needed laparotomy to remove the stone after failed ERCP. T tube removal was after 4-12 weeks post procedure.

Five patients $(6 \%)$ developed a post-operative chest infection. There was no surgery related mortality. Three patients (4\%) were re-admitted within 30 days post-operatively; two were for a bile leak and one due to a post-operative pneumonia.

In univariate analysis, a normal bilirubin level $\mathrm{p}=0.009$, OR 9.9 and CI 2.2-48), a normal CRP ( $\mathrm{p}=0.021$, OR 5.5 and CI 1.04-25) and PDS suture for choledochotomy closure ( $\mathrm{p}=0.01$, OR 5.6 and CI 1.4-23) were significant risk factors for bile leak. Gender (Male/Female), age (Above 70/less than 70 ), White cell count (more than 10 or less than $10^{\star} 9$, size of CBD (more than $12 \mathrm{~mm} /$ less than $12 \mathrm{~mm}$ ), diagnosis (Biliary colic/non-biliary colic) and T-Tube usage had 
Table 2. Shows results of univariate analysis of bile leak risk factors

$\begin{array}{cc}\begin{array}{c}\text { Bile leakage } \\ (n=13)\end{array} & \begin{array}{c}\text { No bile } \\ \text { leakage } \\ (n=49)\end{array}\end{array}$

\begin{tabular}{|c|c|c|c|}
\hline \multicolumn{4}{|l|}{ Demographic factors } \\
\hline \multicolumn{4}{|l|}{ Gender } \\
\hline Male & 3 & 15 & \multirow[t]{2}{*}{0.22} \\
\hline Female & 10 & 34 & \\
\hline \multicolumn{4}{|l|}{ Age } \\
\hline$\geq 70$ years & 4 & 13 & \multirow[t]{2}{*}{0.59} \\
\hline$<70$ years & 9 & 36 & \\
\hline \multicolumn{4}{|c|}{ Presentation (Cholangitis vs Non cholangitis) } \\
\hline Cholangitis & 3 & 13 & \multirow[t]{2}{*}{0.89} \\
\hline Non-cholangitis & 10 & 36 & \\
\hline \multicolumn{4}{|c|}{ Biochemical and structural factors } \\
\hline \multicolumn{4}{|c|}{ Serum leukocytes } \\
\hline$\left(\geq 11 \times 10^{9} / \mathrm{L}\right)$ & 3 & 14 & \multirow[t]{2}{*}{0.44} \\
\hline$\left(<11 \times 10^{9} / L\right)$ & 10 & 35 & \\
\hline \multicolumn{4}{|l|}{ Total bilirubin } \\
\hline ( $\geq 20$ umol/L) & 3 & 40 & \multirow[t]{2}{*}{0.009} \\
\hline (<20 umol/L) & 10 & 9 & \\
\hline \multicolumn{4}{|l|}{ CRP } \\
\hline ( $\geq 20 \mathrm{umol} / \mathrm{L}$ ) & 4 & 34 & \multirow[t]{2}{*}{0.021} \\
\hline (<20 umol/L) & 9 & 15 & \\
\hline \multicolumn{4}{|l|}{ Diameter of CBD } \\
\hline$(<12 \mathrm{~mm})$ & 8 & 27 & \multirow[t]{2}{*}{0.70} \\
\hline$(\geq 12 \mathrm{~mm})$ & 5 & 22 & \\
\hline \multicolumn{4}{|l|}{ Operative technique } \\
\hline \multicolumn{4}{|c|}{ Suture type (Vicryl/PDS) } \\
\hline Vicryl & 8 & 44 & \multirow[t]{2}{*}{0.01} \\
\hline PDS & 5 & 5 & \\
\hline \multicolumn{4}{|l|}{ Technique } \\
\hline Interrupted & 7 & 17 & \multirow[t]{2}{*}{0.24} \\
\hline Continous & 6 & 32 & \\
\hline \multicolumn{4}{|c|}{ Suture size $(2 / 0$ versus smaller than $2 / 0)$} \\
\hline $2 / 0$ & 4 & 29 & \multirow[t]{2}{*}{0.71} \\
\hline Smaller than $2 / 0$ & 9 & 20 & \\
\hline \multicolumn{4}{|c|}{ T-Tube used/T-Tube non-used } \\
\hline T-Tube used & 6 & 10 & \multirow[t]{2}{*}{0.1} \\
\hline T-Tube non used & 7 & 39 & \\
\hline
\end{tabular}

CRP:C-reactive protein; PDSPolydiaxonone suture.

no significant effect on the rate of bile leak (P 0.45 OR 1.6, P 0.97 OR 1.02, P 0.48 OR 1.6, P 0.1 OR 2.7 , P 0.1 OR 1.2 and $\mathrm{P} 0.1$ OR respectively). Normal CRP and normal bilirubin were significantly associated with post emergency LCBDE bile leak on multivariate analysis (0.04 OR 4.1 and 0.009 OR 6.9 respectively) (Tables 2, 3).

\section{Discussion}

Emergency LCBDE and ERCP have equivalent outcomes and are widely accepted procedures for urgent biliary system decompression and both treatments are recommended by published guidelines. ${ }^{[1]}$ The choice of the procedure depends on the endoscopic expertise in ERCP and 
Table 3. Shows results of multivariate analysis of bile leak risk factors

\begin{tabular}{|c|c|c|c|c|}
\hline \multirow[t]{2}{*}{ Risk factors } & \multicolumn{2}{|c|}{ Univariable regression } & \multicolumn{2}{|c|}{ Multivariable regression } \\
\hline & OR $(95 \% \mathrm{Cl})$ & $\mathbf{p}$ & OR $(95 \% \mathrm{Cl})$ & $\mathbf{p}$ \\
\hline Sex (male/female) & $1.6(0.4-6.6)$ & 0.45 & & \\
\hline Age (years) $(\geq 70 /<70)$ & $1.0(0.29-3.7)$ & 0.97 & & \\
\hline Serum leukocytes $\left(\geq 11 /<11 \times 10^{9} / \mathrm{L}\right)$ & $1.6(0.43-6.0)$ & 0.49 & & \\
\hline Total bilirubin ( $\geq 20 /<20$ umol/L) & $9.9(2.0-48.9)$ & 0.0009 & $6.9(1.8-23.9)$ & 0.005 \\
\hline $\operatorname{CRP}(\geq 20 /<20)$ & $5.1(1.0-25.6)$ & 0.023 & $4.1(1.0-17.2)$ & 0.04 \\
\hline Diameter of CBD $(<12 \mathrm{~mm} / \geq 12 \mathrm{~mm})$ & $2.78(0.78-9.9)$ & 0.1 & $1.8(0.81-7.3)$ & 0.4 \\
\hline Presentation (Cholangitis vs Non cholangitis) & $1.2(0.37-3.9)$ & 0.8 & & \\
\hline Method of suture (continuous/interrupted) & $1.3(0.3-5)$ & 0.7 & & \\
\hline Suture type (Vicryl/PDS) & $5.7(1.5-22.1)$ & 0.01 & $5.1002(1.2977-18.2711)$ & 0.04 \\
\hline T-Tube used/ T-Tube non-used & $3.4(0.9-9.9)$ & 0.1 & $2.9(0.84-8.8)$ & 0.1 \\
\hline
\end{tabular}

the degree of surgeon's experience performing LCBDE. LC+LCBDE have been shown to be more cost effective in comparison to LC+ERCP. ${ }^{[12]}$ Furthermore, ERCP has its own specific complications including damage to the sphenicter of Oddi (SOD) which could have significant consequences to patients.

There is still no clear consensus about which modality is the best to treat CBD stones and specifically in the emergency setting. This series is one of very few which have investigated LCBDE in the emergency setting and probably the first one to analyse and predicted risk factors of bile leak following emergency LCBDE. In our study, the conversion rate to open surgery was $4 \%$. This is in line with other published series 5. Duct clearance rate (89\%) in this series is comparable to other emergency LCBDE series and elective LCBDE. ${ }^{[13,14]}$ CBD clearance was achieved in 6 patients who had impacted stones and had prior unsuccessful ERCP. Primary suture of choledochotomies rather than using a t-tube has been established as a preferable technique in the literature. ${ }^{[15]} \mathrm{A} T$ tube was used in small group of patients selectively when there was a doubt about duct clearance or surgeons' preference.

LCBDE may have serious potential complications. One of the important complications that can follow emergency LCBDE is post-operative bile leak. There is wide variability in the bile leak rate reported in the literature. ${ }^{[16-18]}$ Only a small number of series have defined bile leak post LCBDE. ${ }^{[7,19]}$ In our series, bile leak was reported in 13 patients (16 $\%$ ); this is higher than our large series of 300 patients. ${ }^{[8]}$ This is probably because in emergency setting we are doing more challenging cases which either had previous surgery or had unsuccessful ERCP due to impacted stones. One study on emergency LCBDE reported a $6 \%$ bile leak but it did not define bile leak clearly. ${ }^{[5]}$

A published series has found possible associated factors with bile leak in the elective setting such as surgeon's experience and size of bile duct. ${ }^{[7]}$ We found no relation for a bile leak in relation to the size of the CBD. We found a significant difference in relation to the type of suture for suturing the CBD. We found that PDS is associated with a post procedure bile leak. PDS suture has a memory that makes it difficult to manipulate during suturing in comparison to Vicryl this may affect the degree of suturing and knotting security. This is a potentially important finding and certainly warrants further investigation. As this technical choice could have a direct impact on procedural results.

In our analysis, a normal bilirubin and/or a normal C- reactive protein are associated with a post procedure bile leak. This is a difficult result to explain in that we would have expected raised inflammatory markers to indicate local inflammation of the CBD which could increase the risk of a bile leak. Likewise, a raised bilirubin would be conventionally expected to be a risk factor due to a high pressure biliary system. It can be speculated that normal bilirubin might reflect less dilated biliary system which lead to increased risk of bile leak, low CRP might indicates thin wall CBD which makes it less robust during suturing. As such, this finding is difficult to interpret. This warrants further investigation to investigate any preoperative risk factors. 


\section{Limitations}

This is a retrospective series from a single unit. This limits the generalizability of our results. The study size is also relatively small (although comparable to other series). This also limits the range of our conclusions in this study.

\section{Conclusion}

Emergency LCBDE is a safe and feasible procedure for the treatment of emergency presentation CBD stones and it should be considered in the emergency management of bile duct stones.

\section{Disclosures}

Ethichs Committee Approval: Northumbria healthcare foundation trust/2018 approval.

Peer-review: Externally peer-reviewed.

Conflict of Interest: None declared.

Authorship Contributions: Concept - Y.A., L.H.; Design - Y.A., J.B., D.L.; Supervision - L.H., J.B., D.L., Y.A.; Materials - L.H., J.B., D.L., Y.A.; Data collection and/or processing - Y.A.; Analysis and/ or interpretation - Y.A., D.L., J.B.; Literature search - D.L., Y.A.; Writing - Y.A., D.L.; Critical review - D.L., J.B.

\section{References}

1. Everhart JE, Khare M, Hill M, Maurer KR. Prevalence and ethnic differences in gallbladder disease in the United States. Gastroenterology 1999;117:632-9. [CrossRef]

2. Chiarugi M, Galatioto C, Lippolis PV, Puglisi A, Battini A, Scassa $F$, et al. Simultaneous laparoscopic treatment for common bile duct stones associated with acute cholecystitis. Results of a prospective study. [Article in Italian] Chir Ital 2006;58:709-16.

3. Cuschieri A, Lezoche E, Morino M, Croce E, Lacy A, Toouli J, et al. multicenter prospective randomized trial comparing twostage vs single-stage management of patients with gallstone disease and ductal calculi. Surg Endosc 1999;13:952-7.

4. Clayton ES, Connor S, Alexakis N, Leandros E. Meta-analysis of endoscopy and surgery versus surgery alone for common bile duct stones with the gallbladder in situ. Br J Surg 2006;93:1185-91. [CrossRef]

5. Alhamdani A, Mahmud S, Jameel M, Baker A. Primary closure of choledochotomy after emergency laparoscopic common bile duct exploration. Surg Endosc 2008;22:2190-5. [CrossRef]

6. Gurusamy KS, Samraj K. Primary closure versus T-tube drainage after laparoscopic common bile duct stone explo- ration. Cochrane Database Syst Rev 2007;1:CD005641.

7. Liu D, Cao F, Liu J, Xu D, Wang Y, Li F. Risk factors for bile leakage after primary closure following laparoscopic common bile duct exploration: a retrospective cohort study. BMC Surg 2017;17:1. [CrossRef]

8. Aawsaj Y, Light D, Horgan L. Laparoscopic common bile duct exploration: 15-year experience in a district general hospital. Surg Endosc 2016;30:2563-6. [CrossRef]

9. Qiu J, Yuan H, Chen S, Wu H. Laparoscopic common bile duct exploration in cirrhotic patients with choledocholithiasis. Surg Laparosc Endosc Percutan Tech 2015;25:64-8. [CrossRef]

10. Yi HJ, Hong G, Min SK, Lee HK. Long-term Outcome of Primary Closure After Laparoscopic Common Bile Duct Exploration Combined With Choledochoscopy. Surg Laparosc Endosc Percutan Tech 2015;25:250-3. [CrossRef]

11. Wakabayashi G, Iwashita Y, Hibi T, Takada T, Strasberg SM, Asbun HJ, et al. Tokyo Guidelines 2018: surgical management of acute cholecystitis: safe steps in laparoscopic cholecystectomy for acute cholecystitis (with videos). J Hepatobiliary Pancreat Sci 2018;25:73-86. [CrossRef]

12. Rogers SJ, Cello JP, Horn JK, Siperstein AE, Schecter WP, Campbell AR, et al, Harris HW. Prospective randomized trial of LC+LCBDE vs ERCP/S+LC for common bile duct stone disease. Arch Surg 2010;145:28-33. [CrossRef]

13. Noble H, Tranter S, Chesworth T, Norton S, Thompson M. A randomized, clinical trial to compare endoscopic sphincterotomy and subsequent laparoscopic cholecystectomy with primary laparoscopic bile duct exploration during cholecystectomy in higher risk patients with choledocholithiasis. J Laparoendosc Adv Surg Tech A 2009;19:713-20. [CrossRef]

14. Rhodes M, Sussman L, Cohen L, Lewis MP. Randomised trial of laparoscopic exploration of common bile duct versus postoperative endoscopic retrograde cholangiography for common bile duct stones. Lancet 1998;351:159-61. [CrossRef]

15. Zhang LD, Bie P, Chen P, Wang SG, Ma KS, Dong JH. [Primary duct closure versus T-tube drainage following laparoscopic choledochotomy]. Zhonghua Wai Ke Za Zhi 2004;42:520-3.

16. Nathanson LK, O'Rourke NA, Martin IJ, Fielding GA, Cowen AE, Roberts RK, et al. Postoperative ERCP versus laparoscopic choledochotomy for clearance of selected bile duct calculi: a randomized trial. Ann Surg 2005;242:188-92. [CrossRef]

17. Noble H, Whitley E, Norton S, Thompson M. A study of preoperative factors associated with a poor outcome following laparoscopic bile duct exploration. Surg Endosc 2011;25:1309. [CrossRef]

18. Bansal VK, Misra MC, Garg P, Prabhu M. A prospective randomized trial comparing two-stage versus single-stage management of patients with gallstone disease and common bile duct stones. Surg Endosc 2010;24:1986-9. [CrossRef]

19. Zhang GW, Lin JH, Qian JP, Zhou J. Analyzing risk factors for early postoperative bile leakage based on Clavien classification in bile duct stones. Int J Surg 2014;12:757-61. [CrossRef] 